\title{
Colonialidad del poder e historia global: cuestiones abiertas (Homenaje a Aníbal Quijano)
}

\section{Coloniality of Power and Global History: Open Questions (A Tribute to Aníbal Quijano)}

\author{
Daniele Benzi*
}

REsumen: este artículo presenta dos argumentos. El primero sugiere que Aníbal Quijano podría ser considerado el último gran teórico latinoamericano del siglo XX. Ello, a partir de una mirada que ve a la teoría de la "colonialidad del poder" como la síntesis más acabada, hasta la fecha, de las distintas vertientes y problemáticas del pensamiento crítico latinoamericano. El segundo argumento, en cambio, plantea un conjunto de cuestiones abiertas en torno a la arquitectura histórico-conceptual de la "colonialidad" concebida como un "patrón mundial de poder", a la luz de las interpretaciones sobre el ascenso europeo avanzadas en distintas obras de historia global y sociología macrohistórica. Esta parte interroga también su vigencia a raíz de las dinámicas en curso en la economía políitica global del capitalismo. El objetivo es reabrir la discusión sobre la profundidad y el alcance de la "colonialidad" y su "crisis raigal" en una perspectiva teórica no eurocéntrica, pero al mismo tiempo genuinamente histórica y global.

Palabras Clave: Aníbal Quijano; Pensamiento crítico latinoamericano; Colonialidad del poder; Historia global; Sociología macro-histórica; Economía políitica global.

ABSTRACT: This paper presents two arguments. The first suggests that Aníbal Quijano maybe considered the last great Latin American theorist of the 20th century. This is argued from the point of view that looks at his theory of the "coloniality of power" as the most original synthesis to date of the different schools and problems of the Latin American critical thought. On the other hand, the second argument poses a set of open questions regarding the historical-conceptual architecture of "coloniality" conceived as a "new model of power of global vocation". This is argued in the light of fresh interpretations advanced in various works of global history and macro-historical sociology about European world expansion. This part also casts some doubts of its validity in the light of the current trends in the global political economy of capitalism. My aim is to reopen the discussion about the depth and scope of "coloniality" and its "root crisis" in a theoretical perspective that is not Eurocentric, but at the same time is genuinely historical and global.

KeY wORDS: Aníbal Quijano; Coloniality of Power; Latin American critical thought; Global history; Macro-historical sociology; Global political economy.

Recibido: 11 de agosto de 2019

Aceptado: 4 de marzo de 2020

Universidad Federal de Bahía (danielebenzi@hotmail.com). 
Y como todo reencuentro, en plena lucha, es un debate, no una canonización. Aníbal Quijano, José Carlos Mariátegui: reencuentro y debate, 1979

\section{INTRODUCCIÓN}

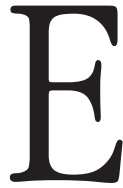

ste artículo es un reconocimiento a un intelectual cuyo pensamiento ha influenciado notablemente no sólo la teoría social y visión de América Latina de varias generaciones de estudiosos y militantes, sino también la esencia misma del entendimiento y práctica del pensamiento crítico latinoamericano. ${ }^{1}$ Fiel a su lección, la forma de reconocer a un maestro como él, no puede ser sino crítica, es decir, no puede sino interrogar su legado para seguir renovando la tradición del pensamiento crítico latinoamericano en el siglo XXI. Este homenaje, en otras palabras, como dijera el propio Aníbal Quijano refiriéndose nada menos que a su reencuentro con Mariátegui en 1979, es un debate, no una canonización.

El artículo presenta dos argumentos. El primero, desarrollado en el siguiente apartado, sugiere que el sociólogo peruano podría ser considerado el último gran teórico latinoamericano del siglo xx. Esta idea surge de la constatación de que la empresa intelectual de Quijano se inscribe y posiblemente constituya el punto de llegada, hasta la fecha, de una tradición de pensamiento crítico iniciada a finales del siglo XIX, cuyos ejes de reflexión se articularon en torno al problema de la identidad de América Latina y a su lugar - político, económico, social y cultural- en el mundo moderno. Desde esta mirada, la teoría o perspectiva de la "colonialidad del poder", en tanto expresión de la fase madura de la obra del sociólogo peruano, simboliza la culminación de esa tradición y no simplemente un

1 Además de ser sometido a un arbitraje doble ciego, el autor quiere agradecer a Inés Fernández Mouján, Victor Coutinho Lage y Marco Narea por sus comentarios a una versión anterior de este artículo. 
avance, ni una ruptura o giro paradigmático como sugieren las lecturas "decoloniales" de su pensamiento. ${ }^{2}$

El segundo argumento, en cambio, esbozado en el tercer apartado, plantea un conjunto de interrogantes o cuestiones, como las definía Quijano, sobre la arquitectura histórico-conceptual de la "colonialidad" concebida como un "patrón mundial de poder", a la luz de las interpretaciones sobre el ascenso europeo avanzadas en distintas obras de historia global y sociología macro-histórica. ${ }^{3}$ Se trata, en otras palabras, de reabrir la discusión sobre la profundidad y el alcance de la "colonialidad del poder" en una perspectiva teórica no eurocéntrica, pero al mismo tiempo genuinamente histórica y global. Asimismo, asumiendo como eje del análisis la contextualización histórica y social del trabajo del propio sociólogo peruano, esta parte del texto interroga también la vigencia de la "colonialidad del poder" a la luz del declive hegemónico estadounidense y de las dinámicas en curso en la economía política global del capitalismo.

En tanto cuestiones abiertas, esto es, hipótesis a explorar más detenidamente en otros trabajos, el objetivo de este artículo/homenaje es delinear una agenda de investigación que, a partir de la teoría social de Aníbal Quijano, contribuya a los grandes debates inscritos en la tradición del pensamiento crítico latinoamericano.

El punto de partida de este ensayo retoma el argumento del teórico neogramsciano Robert W. Cox enunciado en el ámbito de la economía política internacional. En un trabajo seminal para el angosto ámbito disciplinario y disciplinante de las relaciones internacionales, Cox sostuvo que la teoría siempre es "para alguien y para algún propósito" (Cox 2013: 132).

2 Una síntesis sobre el "giro decolonial" del Grupo Modernidad/Colonialidad/Descolonialidad, un colectivo de académicos del cual Quijano formó parte, se encuentra en Escobar (2003) y Ballestrin (2013) entre otros. Una reflexión más amplia en Restrepo y Rojas (2010).

3 Existen varias corrientes y debates en el ámbito de la historia global que no es necesario especificar aquí. Una panorámica en Conrad (2016). Lo mismo vale para los enfoques de sociología histórica y macro-histórica (Collins 1999; Arrighi 2000), sociología histórica de las relaciones internacionales (Hobden y Hobson 2002) y sociología histórica global (Go y Lawson 2017). 
Todas las teorías tienen su perspectiva. Las perspectivas derivan de una posición en el tiempo y el espacio, específicamente de un tiempo y espacio político y social. El mundo es visto desde un punto de vista definible en términos de nación o clase social, de dominación o subordinación, de poder en aumento o en decadencia, de un sentido de inmovilidad o de crisis presente, de experiencia pasada y de esperanzas y expectativas para el futuro (132).

Si bien en su momento el objetivo de Cox fue desvelar de forma discreta y elegante las premisas políticas e ideológicas subyacentes a los paradigmas dominantes de las relaciones internacionales, su advertencia resulta también útil para el examen de las teorías críticas. En este caso, es suficiente recordar que la "perspectiva" del quehacer intelectual de Aníbal Quijano siempre fue aquella de la izquierda y de los movimientos sociales latinoamericanos.

En línea con lo anterior, el método de indagación seguido procede de Perry Anderson (2005). En la introducción de Spectrum, una compilación de agudos ensayos sobre la historia de las ideas y sus autores, el historiador británico afirma que:

$[\mathrm{C}]$ on independencia de su complejidad, las ideas es mejor estudiarlas en la obra detallada de los escritores que las presentan, como textos inseparables de contextos históricos que son a un tiempo sociales y conceptuales, aunque no reducibles a ellos. La opción, en otras palabras, es no tratarlas como motivos intemporales, ni como discursos genéricos, ni como lenguajes especializados, las tres alternativas más populares que se ofrecen (Anderson 2005: XII).

En este sentido, los estudios de interpretación y divulgación de la obra de Aníbal Quijano, aún exiguos pero por suerte en aumento, aquí son considerados de forma secundaria y como complemento. ${ }^{4}$ Asimismo, se hace referencia únicamente a la teoría de la "colonialidad del poder" desarrollada por el sociólogo peruano, dejando para otro espacio la discu-

4 Véase, entre otros, Segato (2013), Assis (2014) y los ensayos recopilados por Pacheco Chávez (2018). 
sión sobre la interpretación y apropiación de otros autores y autoras, en particular de los miembros del Grupo Modernidad/Colonialidad/Descolonialidad y de los seguidores del "giro decolonial", así como sus críticos.

Este artículo/homenaje concluye con algunas consideraciones sobre el intelectual crítico y su papel frente al poder y a la sociedad retomando las reflexiones de Edward W. Said (1996) y Charles Wright Mills (2008).

El intuito inicial de esta exploración descansa sobre una hipótesis y una tesis que es oportuno explicitar desde un comienzo. La hipótesis es relativamente articulada pero sencilla al fin y al cabo. Ella sugiere que toda la teoría social de Aníbal Quijano, y en particular la arquitectura históricoconceptual plasmada en la "colonialidad del poder", tiene su baricentro en un equilibrio dinámico pero inestable entre la noción de "totalidad" de lo "social" y su "heterogeneidad histórico-estructural". Esta tensión es el espejo de la relación dialéctica entre elemento teórico y dato histórico, niveles y ámbitos considerados en el análisis, que caracteriza toda sociología histórica. Su expresión más clara se encuentra en el penetrante artículo "Colonialidad del Poder y Clasificación Social" (Quijano 2000a: 345-356). ${ }^{5}$ Pero ella refleja, también, la "peculiar tensión del pensamiento latinoamericano" y su compleja herencia (Quijano 1990a: 33).

Elaborada en una época de reflujo y fragmentación de las izquierdas a nivel mundial, de hegemonía intelectual de los "pos" y de centralidad en las ciencias sociales de los estudios culturales, la teoría de la "colonialidad del poder" de Quijano representa un esfuerzo para formular una síntesis narrativa coherente, desde América Latina, de la evolución mundial del capitalismo articulando diferentes dimensiones y ámbitos de la vida social (clase/trabajo, género/sexo, raza/etnia/nación, autoridad colectiva/Estado), sin sacrificar su carácter de "totalidad social" (Quijano 1990a; 1992b: 16-20; 2000a: 352-356; 2000b: 313-315). Este rasgo, es decir, la "totalidad" como cualidad a un tiempo histórica y sistémica, es crucial no sólo en el

5 En este trabajo se afirma que "[u]na totalidad histórico-social es en un campo de relaciones sociales estructurado por la articulación heterogénea y discontinua de diversos ámbitos de existencia social, cada uno de ellos a su vez estructurado con elementos históricamente heterogéneos, discontinuos en el tiempo, conflictivos" (354). 
análisis del "sistema-mundo moderno" de Immanuel Wallerstein (1983; 2004), de la cual el sociólogo peruano abreva y a la cual aporta (Quijano y Wallerstein 1992; Quijano 2000b; 2000c), sino más en general en la tradición del marxismo crítico de la cual procede y que desea rebasar por su carácter reduccionista y eurocéntrico (Quijano 1990a; 2000a: 356-381).

Paradójicamente, no obstante, sobreponiendo y juntando de forma imperceptible, o eludiendo más a menudo, la problematización histórica de la relación entre la "totalidad" del "capitalismo" "moderno/colonial" y "eurocéntrico" con la expansión colonial europea, la operación aglutinante del concepto "colonialidad del poder" termina por sacrificar, al revés, la "multiplicidad" y "heterogeneidad" de los procesos históricos y sociales que emergen del carácter igualmente contingente, discontinuo y contradictorio de las estructuras y dinámicas de larga duración observadas desde un prisma global. ${ }^{6}$ En realidad, estos atributos jamás son negados en los escritos del sociólogo peruano. Siempre están presentes en un plano teórico y abstracto y en referencias puntuales (Quijano 1992b: 12-14; 2000a: 347351; 2000b: 293-294, 299-300, 313-315). No obstante, quedan a un lado o desdibujados a la hora de proyectar, históricamente, la "colonialidad del poder" al ámbito global o, dicho de otro modo, cuando la "colonialidad" se torna "patrón mundial".

El resultado, involuntario probablemente, pero no menos problemático hoy, es la sutil y ambivalente generalización de experiencias e historias que posiblemente sean peculiarmente "ibero-euro-atlánticoafro-latinoamericanas" (Quijano 2000b: 288-292). La "colonialidad del poder", en otras palabras, podría ser constitutiva de esa trama de historias cuyos vínculos y articulaciones recíprocas dieron origen a "América". Po-

6 Arif Dirlik (1997) ha presentado un argumento parecido en su pionera crítica a los enfoques poscoloniales.

$7 \mathrm{Al}$ menos en un pasaje Quijano evoca claramente, aunque de forma incidental, la existencia de sociedades que "no tuvieron relaciones de colonialidad porque, precisamente, no fueron colonias europeas, o de modo muy corto y muy parcial (Japón, Taiwan, China)" (2000a: 376). En otros, advierte que la colonización europea varió en intensidad y profundidad. Pero en ningún caso parece reflexionar sobre las implicaciones para la "colonialidad" concebida como "patrón mundial". 
dría ser intrínseca a su trayectoria en época moderna y contemporánea influenciando notablemente o, más bien, co-constituyendo, junto con otras historias, la experiencia material, cognitiva y simbólica de la identidad "europea" y los contornos y dinámicas continentales de la propia "Europa". Podría haber sido el caldo de cultivo de experimentación de varias herramientas y dispositivos de dominación y explotación "europeos", quizás a partir de la categoría "raza". No obstante, cuando se toman en cuenta la duración, profundidad y, sobre todo, la historia anterior al colonialismo occidental, la "colonialidad del poder" como tal, quizás sólo de forma parcial y matizada, sea extrapolable al conjunto del mundo sometido por los imperios europeos y a aquello poscolonial. Del mismo modo, "América" tal vez no sea el único origen y fundamento del "patrón de poder" "capitalista", "moderno/colonial" y "eurocéntrico", como sugieren Quijano y otros autores, Enrique Dussel (1994) por ejemplo.

Ahora bien, la opción teórica del sociólogo peruano fue no sólo útil, sino también consistente con la "perspectiva", en el sentido de Cox mencionado arriba, de comprender y ubicarse en un momento y contexto histórico determinado: aquel de la derrota y reflujo de las izquierdas tradicionales paralelo a las movilizaciones y demandas de las identidades y subjetividades negadas y oprimidas durante lo que se dio en llamar la "larga noche de los quinientos años". Fue congruente, en términos de oposición y resistencia, con el zeitgeist de la edad de oro de la "globalización" y del "unipolarismo" estadounidense y su relato victorioso, el "Fin de la Historia" (Fukuyama 1989), coetáneo y curiosamente consonante con la "condición posmoderna" (Lyotard 1984) como expresión de la "lógica cultural del capitalismo tardío" (Jameson 1992), cuando la experiencia aparentemente sólida de la modernidad comenzó a desvanecerse en el aire (Berman 1988). En síntesis, fue una propuesta intelectual muy oportuna y coherente en los años noventa para aprender, repensar y acompañar en un mundo global las luchas de los pueblos latinoamericanos y caribeños (Quijano 1990a).

Sin embargo, hoy en día sobran indicios de que esa etapa se ha agotado, regional y globalmente, lo cual nos convoca a una discusión pro- 
funda y quizá a una revisión de la reflexión teórica e histórica de Aníbal Quijano. En el mismo artículo citado arriba, Cox afirma que "[c] uanto más sofisticada es una teoría, más reflexiona sobre su propia perspectiva y, a la vez, más la trasciende" aun estando siempre presente (Cox 2013: 132). Y agrega: "[C] omo la realidad cambia, los antiguos conceptos tienen que ser ajustados o rechazados, y los nuevos conceptos deben ser forjados en un diálogo inicial entre el teórico y el mundo particular que intenta comprender" (132). Tal vez este sea ahora el caso de la "colonialidad del poder".

A partir de esta hipótesis, mi tesis es bastante obvia. Puede formularse de la siguiente forma: la crítica al eurocentrismo no es completa y, por lo tanto, será menos eficaz en sus objetivos tanto académicos como, sobre todo, en las demás esferas de la vida social que pretende "descolonizar", si no va de la mano con la constante reinterpretación de los procesos históricos en una perspectiva por supuesto situada, pero también genuinamente global. De lo contrario, correrá el riesgo de alejarse demasiado o hasta divorciarse de ellos.

EL ÚLTIMO GRAN TEÓRICO LATINOAMERICANO

DEL SIGLO XX

El fin de esa historia no ocurrirá quieto, ni pacíficamente. [...] Pagaremos todos, todas sus consecuencias. Pero no todo está dicho, ni decidido, sobre la suerte que correrán, que correremos, sus víctimas. [...] Y en tabla alguna está escrito que seremos siempre derrotados. Es, por el contrario, el momento de romper con las rejas del eurocentrismo y de preparar la otra Historia, la que resultará de las grandes luchas que ya están a la vista.

Aníbal Quijano, ¿El fin de cuál Historia?, 1997

Ante todo es necesaria una aclaración. Sugerir que Aníbal Quijano podría ser considerado el último gran teórico latinoamericano del siglo xx no significa en absoluto ignorar o subestimar otros autores cuyas aportaciones al pensamiento crítico de la región han sido y siguen siendo extraordina- 
rias y de inestimable valor. Pienso, por ejemplo, en Pablo González Casanova, Enrique Dussel o Boaventura de Sousa Santos, entre otros, dando por sentado que la nacionalidad en el caso del filósofo portugués importa poco en este discurso.

Sin embargo, creo que es posible considerar a Aníbal Quijano el último gran teórico latinoamericano del siglo xx por al menos dos razones distintivas. La primera es que desde los años cincuenta ha recorrido todas las etapas de nuestras ciencias sociales, desde la fase centrada en el problema agrario y la marginalidad urbana, transitando por el desarrollo, el imperialismo y la dependencia, hasta llegar a los debates sobre la modernidad, ofreciendo en cada una de ellas contribuciones muy originales y significativas. La segunda razón, mucho más importante, es que posiblemente sea el único intelectual de la región que con la teoría de la "colonialidad del poder", desde los años noventa, se dio a la tarea de esbozar una síntesis, conceptual e histórica, que articulara las problemáticas fundamentales del pensamiento crítico latinoamericano procurando darle proyección global.

En más de un sentido, al yuxtaponer los adjetivos "colonial" y "eurocéntrico" a aquellos de "moderno" y "capitalista", la teoría de Aníbal Quijano no parecería otra cosa que la profundización y ampliación desde una óptica latinoamericanista del análisis del "sistema-mundo" de Wallerstein $(1983 ; 2004)$. Mirándola desde otro ángulo, sin embargo, puede alegarse que ella es el punto de llegada de una reflexión que comienza con las intuiciones de José Martí (1891), José Carlos Mariátegui (1928) y Caio Prado Jr. (1942); transita por la imagen pionera del "capitalismo colonial" de Sergio Bagú (1949) y por el concepto de "colonialismo interno" de Pablo González Casanova (1969) y Rodolfo Stavenhagen (1969); se enriquece con los debates del "estructuralismo cepalino" y la "dependencia" de los años sesenta y setenta; se encuentra con el "sistema-mundo" de Wallerstein en los ochenta, para culminar, finalmente, en la arquitectura histórico-conceptual de los años noventa que se nutre e incorpora otras perspectivas básicamente procedentes, en un sentido amplio, de los estudios culturales. 
En efecto, a partir de un punto de vista original esbozado ya en los sesenta y setenta, es Quijano quien desde el pensamiento crítico latinoamericano abriría definitivamente las puertas a una convergencia sustancialmente completa del enfoque de la "dependencia" con los planteamientos de Wallerstein. El artículo "La americanidad como concepto, o América en el moderno sistema mundial", escrito a cuatro manos y publicado en una fecha altamente simbólica, 1992, posiblemente constituya la mejor prueba de ello (Quijano y Wallerstein 1992). Por otra parte, si los teóricos "dependentistas" y sus herederos en raros casos dieron cabalmente ese paso - las excepciones más notables son André Gunder Frank (1978; 1998), por supuesto, quien inclusive fue mucho más lejos en la última etapa de su fecundo itinerario intelectual, y Theotônio Dos Santos (2002) - , es igualmente cierto que nadie osó o mostró mucho interés en rebasar las fronteras de la economía política.

Desde esta mirada, lo que de verdad asombra de Aníbal Quijano es la amplitud, continuidad y acumulación teórica de su obra a lo largo de más de medio siglo, junto con una prodigiosa capacidad de aprendizaje, cuestionamiento y regeneración intelectual. No un "giro paradigmático", ni un "viraje palpable en su historia intelectual" que, a su vez, introduciría un "giro en la historia del pensamiento crítico latinoamericano y mundial" (Segato 2013: 17 y 36). Por el contrario, a partir de una indagación temprana y un cuestionamiento incesante en torno a lo "social" concebido como una "totalidad" "histórico-estructural" integrada por elementos "heterogéneos", desde mediados de la década de 1980 el sociólogo peruano asumió de manera consciente el reto de renovar, acorde con los tiempos y desde la derrota, la tradición del pensamiento crítico latinoamericano (Quijano, 1990a). En este camino, se reveló cada vez más necesario hacer las cuentas con la tradición marxista y la "heterogénea herencia" del propio Marx (Quijano 2000a: 344). ${ }^{8}$

8 Véase las sutiles observaciones de Quijano (1987) en el Coloquio "iMarx para qué?" y el punto de llegada en su teoría de la clasificación social (2000a: 356-373). Véase también el recuerdo de Roberto Espinoza (2018). 
Se podría objetar que él no fue el único y es cierto. Es indudable, por ejemplo, que los estudios de Enrique Dussel en muchas áreas presentan un carácter más sistemático y analítico que las exploraciones de Quijano. Asimismo, sin abandonar la reflexión sobre la sociología de la explotación, la transferencia del excedente, el Estado y la democracia, las incursiones de Pablo González Casanova en las ciencias de la complejidad han sido muy apreciables y de gran valor. Lo mismo vale para las "epistemologías del Sur" de Boaventura de Sousa Santos.

Sin embargo, a mi manera de ver sólo Aníbal Quijano se aventuró y logró delinear el núcleo y los contornos de una teoría y una historia, esto es, una "teoría histórica" en sus propios términos (Quijano 2000a: 367), que desde América Latina articulase todos los elementos del "patrón de poder mundial" "capitalista", "moderno/colonial" y "eurocéntrico" (Quijano 2000b). Encaró ese desafío consciente de que "[n] adie [sería] inmune a la vasta tempestad intelectual que cubre el planeta" (Quijano 1990a: 3). Y que las ciencias sociales probablemente saldrían completamente reconfiguradas de los torbellinos provocados por el giro lingüístico, posestructuralista y posmoderno; de los estudios subalternos y culturales; de interseccionalidad y de género y, por supuesto, de los estudios poscoloniales, cuyas huellas son patentes en la "colonialidad del poder", si bien no explicitadas (Quijano 2000b: 296).

El sociólogo peruano asumió ese reto a raíz del clima cultural mundialmente dominado por la confusión y el pesimismo en la izquierda seguido al derrumbe del "socialismo real"; al agotamiento, fracaso y destrucción del proyecto político e ideológico del "Tercer mundo"; y al aplastamiento o degeneración de las experiencias de lucha guerrillera y liberación nacional (Quijano 1990a; 1997a; 2003). Una coyuntura que, a pesar de todo, leyó también como oportunidad para la "liberación de la pesada hipoteca intelectual y política que el estalinismo colocó sobre toda la izquierda" (Quijano 1990b: 589). Elaboró su teoría al fragor de los levantamientos indígenas y de las movilizaciones de los afrodescendientes, de los nuevos polos marginales y de los experimentos de economía popular germinados en las grietas del Estado desarrollista y luego florecidos, para bien y 
para mal, de forma paralela a los horrores del Consenso de Washington y del Estado neoliberal (Quijano 1990a; 1998; 2005). Este aspecto tampoco puede dejarse a un lado. A pesar de la sintonía con los movimientos que a caballo del nuevo milenio dieron vida al Foro Social Mundial cultivando la consigna de que "otro mundo es posible", la cuestión del Estado-nación jamás desapareció de su radar intelectual (Quijano 1991; 1997b). Por el contrario, ella constituye uno de los ejes de la teoría de la "colonialidad del poder" (Quijano 2000b: 318-344).

En fin, sobran razones para no sorprenderse del enorme aprecio y consideración no sólo intelectual, sino también humanos, que el sociólogo peruano ha cosechado en los últimos cincuenta años en la mayoría de los espacios que ha atravesado. Un aprecio y respeto inclusive por parte de quienes $-\mathrm{y}$ no son pocos en la izquierda latinoamericana y mundial- no comparten o prefieren ignorar la premisa inquebrantable de su quehacer teórico y político: la "socialización radical del poder", de cualquier forma de poder, es decir, "la devolución a las gentes mismas, de modo directo e inmediato, del control de las instancias básicas de su existencia social" (Quijano 2000a: 381).

Por último, es importante destacar también un elemento que hasta ahora no ha recibido la importancia que merece. La "colonialidad del poder", como "teoría histórica" para la praxis, refleja el esfuerzo y la tensión conceptual de una perspectiva que ha tratado de unir en una época de fragmentación, de sintetizar en la dispersión y articular en la disgregación.

En este sentido considero a Aníbal Quijano el último gran teórico latinoamericano del siglo xx. Su muerte, simbólicamente, completa y posiblemente cierra un ciclo largo de pensamiento crítico en la región. Un ciclo que, no por azar, coincidió con el ascenso y ahora la crisis "terminal" de la hegemonía mundial de Estados Unidos (Arrighi 2007) y, para algunos, también del capitalismo concebido como un sistema histórico (Wallerstein 2013). Un ciclo cuyas premisas fueron sentadas en los años veinte y treinta del siglo pasado y desarrolladas en las décadas de 1960 y 1970, que tuvo su primer reflujo en los años ochenta, se recuperó parcialmente en los noventa y, en particular, a comienzo de este siglo con la (re) 
incorporación, aún frágil e inacabada, de las visiones y demandas de las subjetividades e identidades negadas y oprimidas durante la larga noche de los quinientos años.

La teoría de la "colonialidad del poder" es la síntesis más brillante y el punto de llegada, hasta la fecha, de esta tradición. Como ninguna otra, encarna la peculiar tensión del pensamiento crítico latinoamericano en relación a la identidad de América Latina para desvelarnos la riqueza de su compleja herencia. Una herencia que en estos momentos, sin embargo, pese a la supuesta madurez y vitalidad de nuestro pensamiento (Escobar 2016) y a las actividades frenéticas y espectaculares de redes como Clacso para mantenerlo al día, navega nuevamente en la oscuridad fragmentada de una región sin rumbo, ante un desorden global irreconocible y desconocido.

La obra madura de Aníbal Quijano, en efecto, entraña en sí misma una intrigante paradoja que comparte con otras teorías históricas. Su elaboración y exposición más acabada y elegante se dio de forma paralela a la clara percepción de la profundidad de la crisis de aquello que estaba teorizando. Por ello nos instaba a "preparar la otra Historia" (Quijano 1997: 32).

\section{COLONIALIDAD DEL PODER E HISTORIA GLOBAL: CUESTIONES ABIERTAS}

Este patrón de poder es hoy aún mundialmente hegemónico, pero también en su momento de más profunda y raigal crisis desde su constitución hace poco más de quinientos años.

Aníbal Quijano, "Bien vivir". Entre el "desarrollo" y la des/colonialidad del poder, 2011.

No es ningún misterio, ni tampoco un problema, sino todo lo contrario, que desde finales de los setenta y particularmente en los últimos veinte años, las intervenciones de Aníbal Quijano tuvieron casi siempre, pese a la continuidad de las cuestiones abordadas, un "carácter exploratorio" 
(Assis 2014: 15-16). Tal vez resida precisamente ahí su intuito, originalidad y capacidad para abrir incesantemente nuevas pistas de reflexión, análisis y debate.

En este sentido, son únicamente dos los textos en los cuales el sociólogo peruano ha tratado de exponer de forma sistemática todos los elementos que abarca su teoría. Ambos fueron publicados en 2000 y republicados en distintas ocasiones (Quijano 2000a; 2000b). De ellos y demás artículos escritos desde finales de los ochenta, de la "colonialidad del poder" como concepto-síntesis y eje transversal de sus indagaciones se infieren por lo menos: 1) una teoría histórica del "capital", esto es, del "capitalismo" (Quijano 1993; 2000a; 2000b; 2000c); 2) una teoría histórica de la "clasificación social" (Quijano 1992a; 1999; 2000a; 2000b); 3) una teoría histórica de la "modernidad" y del "eurocentrismo" (Quijano 1990a; 1992b; 2000a; 2000b), y por último 4) una teoría histórica del "Estado-nación" (Quijano 1991; 1997b; 2000b; 2000c).

Subyacente y oblicua a ellas, es decir, a su articulación "histórico-estructural", también se halla el esbozo de una teoría general del "poder". Ésta es explícita en ocasiones, pero la mayoría de las veces opera implícitamente. El "poder social" es concebido por Quijano de forma tríadica y relacional, como pura negatividad. Sus elementos constitutivos son relaciones de "dominación/explotación/conflicto" por el control de los "recursos" y "productos" de lo que considera los principales ámbitos, o "áreas vitales", de la existencia social: el trabajo, el sexo, la subjetividad y la autoridad colectiva (Quijano 2000a; 2001). El campo o los campos del poder articulan "tramas" o "mallas" de relaciones materiales e intersubjetivas dentro y entre estos ámbitos. Éstas se estructuran a su vez en "configuraciones más amplias" (2001: 7) que atraviesan "toda la experiencia social de todas las gentes, en todas partes y en todos los tiempos" (4). En fin, "toda la historia de nuestra especie" (4). Pero de forma heterogénea. Sólo en este sentido específico, afirma, "tales campos de relaciones tienen el carácter de una totalidad" (7).

De este modo, el poder constituye para Quijano el principal motor del cambio social, es decir, de la historia. "Hasta donde sabemos - sostie- 
ne en una de sus últimas intervenciones- el poder parece haber sido, en toda la historia conocida, no solamente un fenómeno de todas las existencias sociales de larga duración, sino, más aún, la principal motivación de la conducta histórica colectiva de la especie" (Quijano 2011: 86). No obstante, el sociólogo peruano aborda esta cuestión crucial de forma directa en un solo texto (Quijano 2001). Al igual que en otros, toma como referencia para construir su argumento la concepción del poder del "liberalismo" y del "materialismo histórico", en un sentido amplio, así como del estructural-funcionalismo y del posmodernismo (Quijano 2000a: 345356; 2001). Su objetivo es mostrar el carácter ahistórico o transhistórico y, en definitiva, eurocéntrico de estas teorías. Sin embargo, la relación entre fundamento teórico-especulativo, en su dimensión ontológica y epistémica, y piso histórico, es poco desarrollada en sus textos y totalmente desbalanceada hacia el primer elemento. Más en general, con contadas excepciones y casi todas relativas al continente americano, en la obra madura del sociólogo peruano es palpable un hueco entre las menciones a la "vida social de la especie", la "historia conocida" y de las "gentes", por un lado, y el inicio de la expansión europea, es decir, de su específico "patrón de poder", la "colonialidad", por el otro.

Ahora bien, si la "globalización" es, como sostiene Quijano, "la culminación de un proceso que comenzó con la constitución de América y la del capitalismo colonial/moderno y eurocentrado como un nuevo patrón de poder mundial" (2000b: 281), no hay que olvidar que en sus trabajos figura siempre, también, la nítida percepción de su crisis actual. En uno de los últimos afirma incluso que a pesar de ser "aún mundialmente hegemónico, [este patrón de poder] también [se encuentra] en su momento de más profunda y raigal crisis desde su constitución hace poco más de quinientos años" (Quijano 2011: 77-78).

Desde la economía política global con la que el sociólogo peruano tuvo más afinidad, se podría sostener que la crisis "terminal" de la hegemonía mundial estadounidense (Arrighi 2007) comenzada en 2003 con la invasión de Irak y entrada en su recta final tras la crisis financiera de 2008, además de cerrar el "largo siglo xx", nos estaría aproximando también al 
fin de los ciclos hegemónicos del "sistema-mundo capitalista" (Wallerstein 2013). ¿Otro "fin de la historia”? ¿Un "caos sistémico" sin fin? ¿O "el fin de cuál Historia"?

Aníbal Quijano no logró o no quiso, públicamente al menos, considerar las implicaciones para su teoría sino de forma embrionaria. De haberlo hecho, sin embargo, tal vez algunas de las preguntas iniciales hubieran sido las siguientes: ¿el fin de la dominación mundial occidental qué consecuencias tendría sobre la "colonialidad" como "patrón mundial de poder"? ¿El conjunto de teorías históricas que la sustentan son aún idóneas para interpretar el momento actual a nivel global? ¿Nos ayudan a comprender la situación de América Latina, en particular después del "ciclo progresista"? Si las respuestas fueran parcial o totalmente negativas, ¿qué elementos habría que afinar, corregir o de repente abandonar?

Un proverbio yugoslavo mencionado por Wallerstein (2003) asegura que "[l] a única cosa absolutamente cierta es el futuro, porque el pasado cambia constantemente". 'Hace tiempo la sociología macro-histórica y la historia global están tratando de devolvernos una imagen no eurocéntrica del pasado. De diferentes maneras y con distintos objetivos, se están repensando aquellos que Arrighi (1998) denominó, en retrospectiva, los "no debates" de los setenta sobre los orígenes del capitalismo y el ascenso europeo entre científicos sociales marxistas como Robert Brenner, neomarxistas como Wallerstein y Frank, y neoweberianos como Theda Skopcol, Charles Tilly y Michael Mann.

Algunas contribuciones fundamentales llegaron de la historia comparada y sincrónica de los Imperios y de los imperialismos para observar la época moderna más allá de la formación y expansión del Estado-nación (Ferro 2000; Abernethy 2000; Darwin 2012). Se ha revisitado la historia económica mundial "re-orientando" el "milagro europeo" y la "gran divergencia" a principios o hasta mediados del siglo XIX (Wong 1997; Frank

9 Wallerstein, por otra parte, lo retoma de un artículo de E. M. Simonds-Duke de 1987 en el cual, a su vez, figura como epígrafe. Y cabe la pregunta hoy: iproverbio yugoslavo? ¿de cuál nación, pueblo, etnia, raza o religión - de cuál historia, en fin, o historias- procede un dicho tan sugerente? 
1998; Pomeranz 2000). Se ha impugnado exitosamente el eurocentrismo en su pretensión de asignar a los "europeos" una patente de originalidad o, mejor dicho, singularidad y excepcionalidad en el desarrollo de un tipo de racionalidad superior y autogenerada, particularmente apta para la innovación científica y tecnológica (Blaut 1993; Goody 1996; Hobson 2004). Asimismo, en el ámbito del análisis inaugurado por Wallerstein, se ha problematizado teórica e históricamente la cuestión de la fronteras espaciales y temporales de la expansión del "sistema-mundo", es decir, el problema de la coexistencia durante un largo periodo de tiempo de diferentes sociedades y sistemas sociales (Terlouw 1992; Mielants 2007). Últimamente, Anievas y Nişancioğlu (2015) han delineado un ambicioso enfoque basado en la teoría del desarrollo desigual y combinado elaborada originalmente por Trotsky y retomada en la sociología histórica de las relaciones internacionales hace ya un par de décadas, para narrar una historia diferente de "cómo Occidente llegó a dominar".

Varias cuestiones abordadas en estos estudios coinciden con las inquietudes intelectuales de Quijano y, aunque indirectamente, interpelan la teoría de la "colonialidad del poder". En su amplísima variedad, estos trabajos comparten la premisa de que de una u otra forma hay que seguir repensando los orígenes, la dinámica, el alcance y la profundidad de la expansión europea y del capitalismo occidental a lo largo y ancho de los últimos quinientos años. Dicho en otras palabras, "[s] i bien [el legado del] gobierno colonial formal [...] es vivo todavía, influenciando el mundo poscolonial de forma tanto obvias cuanto sutiles" (Abernethy 2000: X, TdA), no menos cierto es que:

$[\mathrm{P}]$ arece necesario tomar en cuenta el pasado de esas sociedades, pues la relación entre colonizadores y colonizados dependió mucho de él. [...] Esos pueblos no eran semejantes, uniformes so pretexto de que aún no habían sido colonizados; y así como una colonización pudo diferir de otra, también la respuesta de las sociedades conquistadas varió en relación con su pasado e identidad propia. Además, sería difícil comprender por qué el análisis histórico reproduciría una visión del pasado que europeíza el fenómeno colonial. Sin duda, durante cinco siglos los europeos lo encarnaron bien, y de ese modo consolidaron la unificación del mundo. Más otras 
colonizaciones contribuyeron también a dar forma a la imagen actual del planeta (Ferro 2000: 14).

En síntesis, "[e]s posible que dos fechas clave, 1492 (cuando Colón cruzó el Atlántico) y 1498 (cuando Vasco da Gama llegó a la India) marcan el inicio de una nueva era para Europa. Sin embargo, el avance fue espasmódico en todos los casos" (Darwin 2012: 39).

Aníbal Quijano mostró siempre plena conciencia de ello (Quijano 1968: 528; 1980: 29-31; 1992b: 13; 2000a: 376; 2000b: 293-294; 2011: 86). Sin embargo, nunca se detuvo a explorar las posibles implicaciones para el concepto de "colonialidad" como "patrón mundial". El mundo de hoy, no obstante, nos obliga a reabrir esta cuestión. Ello parece necesario no sólo para entender mejor la heterogeneidad y articulación de las formas político-institucionales, económicas, culturales e intersubjetivas que asumió el globo en los quinientos años de despliegue occidental. Sino también para ubicarse, desde América Latina, en el momento presente. Un presente en el cual el poder material y simbólico de los Estados europeos se encuentra en una nueva fase de aguda crisis y disgregación interna. En el que después de Estados Unidos los principales actores geopolíticos y económicos mundiales son Rusia y China, dos eximperios seculares, milenario en el caso chino y sólo parcialmente europeo en el caso de Rusia, sometidos al dominio occidental únicamente por brevísimos periodos. $\mathrm{Su}$ carácter capitalista y hasta imperialista en la actualidad no le resta relevancia a la cuestión, sino todo lo contrario. Un presente en el que, por último, los movimientos que abogaron por "otro mundo posible" han sido neutralizados, cooptados o derrotados por el momento.

A partir de estas consideraciones, es posible esbozar algunas preguntas iniciales relativas a los cuatro ejes de la perspectiva de la "colonialidad del poder". En primer lugar, ila teoría histórica del "capitalismo" de Quijano no estará demasiado anclada, a pesar de especificarla, a la visión del "sistema-mundo" de Wallerstein compartiendo con ella sus principales límites? ¿Cómo se desarrolló históricamente la "división racial del trabajo" y cómo opera actualmente? ¿Cómo se articulan bajo el capital todas las formas conocidas de control del trabajo? ¿Y las nuevas? ¿Cómo pensar la 
relación entre desarrollo mundial del capitalismo y los persistentes conflictos geopolíticos entre potencias? Finalmente, aun asumiendo integralmente la crítica de Quijano al reduccionismo eurocéntrico del marxismo y del propio Marx, el concepto de "clase" asociado a la explotación del trabajo, ¿no es demasiado útil todavía en la sociología y economía política críticas para disolverse por completo en una teoría de la "clasificación social" de las "gentes"? (Quijano 2000a: 356-373).

Segundo, desde una mirada global, la teoría histórica de la "clasificación social" que sustenta la "colonialidad del poder", ¿no concede excesiva prioridad a la categoría "raza" en detrimento de otras, como por ejemplo la de "etnia" (tribu, clan, casta) y "nación", que no son meros derivados de la primera, o a la religión por ejemplo? Aun cuando no todos los procesos de subjetivación y formación de identidades colectivas puedan ser reconocidos como procesos de clasificación social (Quijano 2000a: 371), ¿cómo desconocer el binomio dominación/explotación en los conflictos étnicos, nacionales y religiosos que no son prerrogativa de la colonización europea y de su herencia, aunque siempre fueron manipulados por ella y por lo general bastante exitosamente? Articulados al racismo a menudo, pero no siempre en todo caso, estos conflictos son cruciales para observar, más allá de la experiencia europea y americana, el auge y a veces la caída de los Imperios modernos (Darwin 2012). Lo son para apreciar la dinámica de formaciones estatales y sistemas económicos regionales e interestatales no europeos (Arrighi et al. 2003; Hamashita 2008; Kang 2010). Finalmente, lo son para comprender el presente en distintas áreas del planeta. Por otra parte, ¿Quijano no estará privilegiando una línea histórica de la categoría "raza", aquella construida a partir de "América", relegando otra, la antisemita? (Fredrickson 2002). Si bien es mencionada en términos genealógicos (Quijano 1992a; 2000b), isu historia no es igualmente importante para explicar elementos y dinámicas clave del mundo moderno y contemporáneo parcialmente independientes de la "colonialidad"? En fin, "raza" es indudablemente un dispositivo fundamental de la clasificación social de la población mundial originada del colonialismo europeo. Pero podría no ser su "piedra angular" (Quijano 2000a: 342), ni 
mucho menos la "piedra fundacional de la estructura de todo el poder del capitalismo mundial" (Quijano 2001: 12). Por otro lado, a esta altura de la investigación histórica, quizás no convenga restringir la mirada a una sola línea de interpretación que defiende la continuidad del fenómeno racista minimizando su variedad, heterogeneidad, discontinuidad y flexibilidad, así como las mutaciones sufridas a raíz de la abolición de la esclavitud, del pasaje de la hegemonía británica a la estadounidense y después de la segunda guerra mundial.

Finalmente, al igual que otros autores, Quijano considera el "eurocentrismo" como una teoría de la historia y de la cultura, una ideología e, inclusive, como el sentido común del "etnocentrismo europeo" (2000b: 293-318). Sin embargo, lo asocia también a un concepto de "modernidad" que, a partir de 1492, inauguraría un "nuevo espacio/tiempo", "un entero universo de nuevas relaciones materiales e intersubjetivas" (304-305). En este sentido, el eurocentrismo es también una "perspectiva de conocimiento" y un "modo de producir conocimiento" ligado a la clasificación racial de la población mundial, es decir, a la "colonialidad del poder". Como tal, fundándose en la paradójica combinación de evolucionismo newtoniano y dualismo cartesiano (307-318), habría servido y seguiría sirviendo como dispositivo de control de la intersubjetividad mundial. Ahora bien, por debajo de los mitos eurocéntricos, de sus discursos y racionalizaciones etnocéntricas, ¿Quijano no estará simplificando la complejidad de los procesos seculares de difusión, transmisión, apropiación y asimilación de las ideas a nivel global? Parafraseando el juego de palabras de Hobson (2004) sobre la leyenda de la diferencia constitutiva entre "Occidente" y "Oriente”, ino estará soslayando las raíces filosóficas, científico-tecnológicas y culturales no europeas del eurocentrismo? No concediendo espacio casi a la discusión sobre su carácter históricamente discontinuo, heterogéneo y contradictorio, ino se corre el riesgo de presentarlo como una especie de "ontología" europea tal y como pretende la fábula eurocéntrica?

En fin, aun sin abordar su teoría general del poder y la ausencia, en su obra madura, de una reflexión geopolítica más sustancial sobre la "co- 
lonialidad", es indudable que existe una mina de cuestiones abiertas y horizontes por explorar del fértil legado de Aníbal Quijano.

REPRESENTACIÓN DEL INTELECTUAL.

A MODO DE CONCLUSIÓN

[e]l hecho decisivo es que el intelectual es un individuo dotado de la facultad de representar, encarnar y articular un mensaje, una visión, una actitud, filosofía u opinión para y en favor de un público. Este papel tiene una prioridad para él, no pudiendo desempeñarlo sin el sentimiento de ser alguien cuya misión es la de plantear públicamente cuestiones embarazosas, contrastar ortodoxia y dogma (más bien que producirlos), actuar como alguien al que ni los gobiernos ni otras instituciones pueden domesticar fácilmente, y cuya razón de ser consiste en representar a todas esas personas y cuestiones que por rutina quedan en el olvido o se mantienen en secreto.

Edward W. Said, Representaciones del intelectual, 1996.

En medio de nubarrones políticos y turbulencias económicas, el 31 de mayo de 2018 falleció en Lima el último gran teórico latinoamericano del siglo XX. Al igual que otros gigantes del pensamiento crítico, en Aníbal Quijano se conjugaron de forma brillante y generosa la inteligencia, la ética y la pasión civil. El fruto que nos ha legado, incómodo y olvidado en tiempos espectaculares y de narcisismo académico, es "el arte de pensar simultáneamente la vida social en términos intelectuales, morales y políticos" (Germaná 2006).

A hombres y mujeres como él parecieran dirigidas las palabras de Edward W. Said que retratan al intelectual como "alguien cuya misión es la de plantear públicamente cuestiones embarazosas, contrastar ortodoxia y dogma [...] alguien que ni los gobiernos ni otras instituciones pueden domesticar fácilmente" (1996: 30). Independiente e insumiso, eso es, por naturaleza, el intelectual crítico. Inspiración y reserva moral de la humani- 
dad. Consciente como pocos de estar equipado "para ofrecer resistencia y combatir el proceso de estereotipación y la muerte consiguiente de las cosas dotadas de vida genuina" (Wright Mills 2008: 19).

En este homenaje, al contextualizar histórica y socialmente la reflexión de la fase madura del pensamiento de Aníbal Quijano, he argumentado básicamente dos cosas. Primero, que la teoría de la "colonialidad del poder" se entiende mejor como la actual culminación, y no la ruptura, del núcleo mismo desde el cual hace poco más de un siglo brotó esa tradición que se iría (re)conociendo y organizando como "pensamiento crítico latinoamericano". Y, segundo, que la "colonialidad del poder", concebida como un "patrón mundial", podría ser más útil pensarla histórica y globalmente, evitando convertirla en un discurso genérico, un motivo intemporal o, peor aún, un lenguaje especializado para iniciados.

A partir de esta mirada, en la segunda parte del texto he planteado un conjunto de cuestiones que posiblemente permitan abrir nuevas pistas de análisis sobre su alcance y profundidad, con el fin de arrojar alguna luz sobre el "momento de más profunda y raigal crisis desde su constitución hace poco más de quinientos años" (Quijano 2011: 77-78). Se trata de unas hipótesis cuya indagación quisiera contribuir, desde la perspectiva crítica encarnada por el sociólogo peruano, a los grandes debates sobre la(s) identidad(es) de América Latina y su lugar - político, económico, social y cultural— en el mundo moderno y contemporáneo.

El momento presente de gran confusión, incertidumbre y también de profundo desencanto tras los extraordinarios movimientos de resistencia al neoliberismo que a principio de este siglo, para bien y para mal, cristalizaron en el "giro a la izquierda" y en las experiencias "progresistas", es particularmente propicio para este tipo de reflexión. Sobre todo a la luz de la nueva embestida conservadora en la región. Pero aún más lo es, quizás, el escenario caótico más amplio que nos depara la crisis terminal de la hegemonía mundial estadounidense y la economía política global del capitalismo.

En cualquier caso, hoy más que nunca es aconsejable prudencia y sobriedad en relación con la eventual fuerza de emancipación y liberación 
que en ocasiones emana de los conceptos y teorías críticas. Inclusive, o sobre todo, al interior del limitado espacio que las estructuras burocráticas y ambientes universitarios dejan en la actualidad a la "imaginación sociológica" (Wright Mills 1959) del hodierno bomo academicus (Bordieu 1984). Indudablemente, "la manera en que visualizamos e interpretamos el pasado tiene enormes consecuencias en la forma en cómo imaginamos el futuro" (Mielants 2007: X, TdA). Sin embargo, como bien mantuvo Arif Dirlik a propósito de la promesa "poscolonial":

[Si] la teoría puede desentrañar la naturaleza de la explotación y de la opresión, [...] no proporciona en sí misma y por sí misma respuestas [a la cuestión fundamental de la relación entre conocimiento y vida cotidiana]. La historia puede aportarnos un inventario de posibilidades, pero no ofrece soluciones al problema de la elección, excepto en sus versiones teleológicas [...]. La teorización de la historia, así como la historicización de la teoría, puede ayudar a ubicarnos en el espacio y en el tiempo proporcionándonos algún sentido sobre qué alternativas podrían ser apropiadas, pero eso es todo (1997: 16, TdA).

Al final del día, el problema fundamental del intelectual crítico seguirá siendo el del equilibrio "entre la soledad y el alineamiento" (Said 1996: 39). Entre la indiferencia o la persecución, según la época y la circunstancia, y las seducciones del poder. Bien lo sabía Aníbal Quijano. Pero no por ello, "dentro" o "fuera" que esté, "aunque sea como minoría de a uno", renuncia a su actitud vital e inquebrantable, estar siempre en contra. Y esta es, en definitiva, la razón más íntima de este sincero y sentido homenaje. 
BIBLIOGRAFÍA

ABERneTHY, DAVID. The Dynamics of Global Dominance. Londres: Yale University Press, 2000.

Anderson, Perry. Spectrum. From Right to Left in the World of Ideas. Londres: Verso, 2005.

Anievas, AleXAnder y Kerem Ni Ancio Lu. How the West Came to Rule. The Geopolitical Origins of Capitalism. Londres: Pluto Press, 2015.

ARRIGHI, GIOVANNI. "Capitalism and the Modern World-system: Rethinking the Nondebates of the 1970". Review 1 (1998): 113-129.

"Globalization and Historical Macrosociology". Janet AbuLughod (ed.). Sociology for the Twenty-First Century. Continuities and Cutting Edges. Chicago: Chicago University Press, 2000. 117-133. Adam Smith in Beijing. Lineages of the Twenty-First Century. Nueva York: Verso, 2007.

Arrighi, Giovanni, Takeshi Hamashita y Mark Selden (eds.). The Resurgence of East Asia. 500, 150 and 50 year Perspectives. Nueva York: Routledge, 2003.

Assis, Danilo. "Prólogo". Aníbal Quijano. Cuestiones y horizontes. Antología esencial. Buenos Aires: Clacso, 2014. 13-53.

Bagú, Sergio. Economía de la sociedad colonial. Buenos Aires: El Ateneo, 1949.

Ballestrin, LuCiANa. "América Latina e o giro decolonial". Revista Brasileira de Ciência Política 11 (2013): 89-117.

Berman, MarShall. All That Is Solid Melts into Air: The Experience of Modernity. Nueva York: Penguin Books, 1988.

Blaut, James M. The Colonizer's Model of the World. Londres: Guilford Press, 1993.

Bordieu, Pierre. Homo Academicus. París: Les Editions de Minuit, 1984.

Conrad, Sebastian. What is Global History? Princeton: Princeton University Press, 2016.

Coluins, Randald. Macrohistory. Essays in Sociology of the Long Run. Stanford: Stanford University Press, 1999. 
COX, ROBERT W. "Fuerzas sociales, estados y órdenes mundiales: más allá de la teoría de relaciones internacionales". Relaciones Internacionales 24 (2013): 129-162.

DARWIN, JoHn. El sueño del imperio. Auge y caída de las potencias globales 1400-2000. Madrid: Taurus, 2013.

DirLIK, ARIF. The Postcolonial Aura: Third World Criticism in the Age of Global Capitalism. Colorado: Westview Press, 1997.

Dussel, ENRIQue. 1492. El encubrimiento del Otro. Hacia el origen del mito de la modernidad. La Paz: Plural Editores, 1994.

ESCOBAR, ARTURO. "Mundos y conocimientos de otro modo. El programa de investigación de modernidad/colonialidad latinoamericano". Tabula Rasa 1 (2003): 51-86.

- "Desde abajo, por la izquierda y con la Tierra: la diferencia de Abya Yala/Afro/Latino-América”. vvAA. Rescatar la esperanza. Más allá del neoliberalismo y el progresismo. Barcelona: Entrepueblos, 2016. 337-369.

ESPINOZA, ROBERTO (2018). "Aníbal Quijano: vivir contra el poder, contra todo tipo de poder". Artículo en línea disponible en https://quijanodescolonial.blogspot.com/2018/11/2018-roberto-espinoza-anibal-quijano.html [Consultado el 10 de julio de 2019].

FERRO, MARC. La colonización. Una historia global. México: Siglo XXI, 2000.

FRANK, ANDrÉ G. World Accumulation, 1492-1789. Nueva York: Monthly Review Press, 1978.

ReOrient: Global Economy in the Asian Age. Berkeley: University of California Press, 1998.

FuKuYAma, Francis. "The End of History?". The National Interest 16 (1989): 3-18.

GermanÁ, CÉSAR (2010). "Aníbal Quijano: el arte de pensar simultáneamente la vida social en términos intelectuales, morales y políticos". Artículo en línea disponible en http://martintanaka.blogspot. com/2006/11/csar-german-sobre-anbal-quijano.html [Consultado el 10 de julio de 2019]. 
Go, Julian y George Lawson (ed.). Global Historical Sociology. Cambridge: Cambridge University Press, 2017.

González Casanova, Pablo. Sociología de la explotación. México: Siglo XXI, 1969.

Goody, Jack. The East in the West. Cambridge: Cambridge University Press, 1996.

HAMASHITA, TAKeSHI. China, East Asia and the Global Economy: Regional and Historical Perspective. Linda Grove y Mark Selden (eds.), Routledge: 2008.

Hobden, StePhen y John M. HobSon (eds.). Historical Sociology of International Relations. Cambridge: Cambridge University Press, 2002.

Hobson, John M., The Eastern Origins of Western Civilisation. Cambridge: Cambridge University Press, 2004.

- The Eurocentric Conception of World Politics. Western International Theory, 1760-2010. Cambridge: Cambridge University Press, 2012.

JAMESON, FREDRIC. Postmodernism, or The Cultural Logic of Late Capitalism. Durham: Duke University Press, 1992.

KAnG, David. East Asia Before the West: Five Centuries of Trade and Tribute. Nueva York: Columbia University Press, 2010.

LyOTARD, JeAn-FrançoIs. The Postmodern Condition: A Report on Knowledge. Minneapolis: University of Minnesota, 1984.

MARIÁTEGUI, José CARLOS. Siete ensayos de interpretación de la realidad peruana. Lima: Amauta, 1928.

MARTí, José. "Nuestra América". La Revista Ilustrada de Nueva York. Nueva York: 1891.

Mielants, ERIC. The Origins of Capitalism and the "Rise of the West". Philadelphia: Temple University Press, 2007.

PACHeCO CHÁvez, Víctor H. (coord.). Rompiendo la jaula de la dominación. Ensayos en torno a la obra de Aníbal Quijano. Santiago de Chile: Doble Ciencia Editorial, 2018.

Pomeranz, Kenneth. The Great Divergence. Princeton: Princeton University Press, 2000. 
Prado, CaIo JR. Formação do Brasil Contemporâneo. São Paulo: Livraria Martins Editora, 1942.

QujJANO, ANíBaL. "Dependencia, cambio social y urbanizacion en Latinoamerica". Revista Mexicana de Sociología 303 (1968): 525-570.

- Dominación y cultura. Lo cholo y el conflicto cultural en el Perú. Lima: Mosca Azul Editores, 1980.

"La tensión del pensamiento latinoamericano". Hueso Húmero 22 (1987): 106-125.

- Modernidad, identidad y utopía en América Latina. Quito: Editorial El Conejo, 1990a.

. "La crisis en Europa del Este y la Izquierda en América Latina". Cultura Libre. 1990b.

. "La razón del Estado". Henrique Urbano (comp.) y Mirko Lauer (eds.). Modernidad en los Andes. Cusco: Centro de Estudios Regionales Andinos "Bartolomé de Las Casas", 1991. 97-120.

. "'Raza', 'Etnia' y 'Nación' en Mariátegui: cuestiones abiertas". Roland Forgues (ed.). José Carlos Mariategui y Europa: el otro aspecto del descubrimiento. Lima: Amauta, 1992a. 167-188.

. "Colonialidad y modernidad-racionalidad". Perú Indigena 13 29 (1992b): 11-20.

- "América Latina en la economía mundial". Problemas del Desarrollo XXIV 95 (1993): 43-59.

-. "¿El fin de cual historia?" Análisis Político 32 (1997a): 27-32.

. "Estado-nación, ciudadanía y democracia: cuestiones abiertas". Helena González y Heidul Schmidt (org.). Democracia para una nueva sociedad. Caracas: Nueva Sociedad, 1997b. 139-155.

Lima: Mosca Azul Editores/CEIS-CECOSAM, 1998.

. "iQué tal raza!". Ecuador Debate 48 (1999): 141-152.

. "Colonialidad del poder y clasificación social". Journal of World Systems Research VI 2 (2000a): 342-386.

Edgardo Lander (ed). La colonialidad del saber: eurocentrismo y 
ciencias sociales. Perspectivas latinoamericanas. Caracas: FACES/ UCV UNESCO, 2000b. 281-348.

. "El fantasma del desarrollo en América Latina". Revista del CESLA 1 (2000c): 38-55.

. (2001) "La colonialidad y la cuestión del poder". Artículo en línea disponible en https://quijanodescolonial.blogspot.com/2017/11/2001la-colonialidad-y-la-cuestion-del.html [Consultado el 10 de julio de 2019].

(2003). "Allende otra vez: en el umbral de un nuevo periodo histórico". Artículo en línea disponible en https:/quijanodescolonial. blogspot.com/2017/11/2003-allende-otra-vez-en-el-umbral-de.html [Consultdo el 10 de julio de 2019].

"El 'movimiento indígena' y las cuestiones pendientes en América Latina”. Revista Tareas 119 (2005): 31-62.

. "José Carlos Mariátegui: reencuentro y debate". José Carlos Mariátegui. 7 ensayos de interpretación de la realidad peruana. Caracas: Fundación Biblioteca Ayacucho, 2007: IX-CXII.

. "¿Bien vivir?: entre el 'desarrollo' y la des/colonialidad del poder". Ecuador Debate 48 (2013): 77-87.

e ImMANUEl WALleRSTEIN. "La americanidad como concepto, o América en el moderno sistema mundial". Revista Internacional de Ciencias Sociales XuIV 4 (1992): 583-591.

RESTEPO, EDUARDO y AXEL ROJAS. Inflexión decolonial: fuentes, conceptosy cuestionamientos. Quito: Editorial Universidad del Cauca, 2010.

SAID, EDWARD W. Representaciones del intelectual. Barcelona: Paidós, 1996.

Santos, Theotônio Dos. La teoría de la dependencia. Balances y Perspectivas. Madrid: Plaza Janés, 1992.

SEGATO, RITA. La crítica de la colonialidad en ocho ensayos y una antropología por demanda. Buenos Aires: Prometeo Libros, 2013.

Stavenhagen, Rodolfo. Las clases sociales en las sociedades agrarias. México: Siglo XXI, 1969. 
Terlouw, Cornelis PeTER. Regional Geography of the World-System. Utrecht: State University of Utrecht, 1992.

Wallerstein, Immanuel. Historical Capitalism with Capitalist Civilization. Londres: Verso, 1983.

. The Decline of American Power. Nueva York: The New Press, 2003.

World-system Analysis. An Introduction. Durham: Duke University Press, 2004.

"Structural Crisis, or why Capitalists may no Longer find Capitalism Rewarding". Does Capitalism have a Future? Nueva York: Oxford University Press, 2013.

, Randall Collins, Michael Mann, Georgi Derluguian, Craig Calhoun. Does Capitalism Have a Future? Nueva York: Oxford University Press, 2013: 9-35.

Wong, R. Bin. China Transformed. Historical Change and the Limits of European Experience. Ithaca: Cornell University Press, 1997.

Wright Mills, Charles. The Sociological Imagination. Nueva York: Oxford University Press, 1959.

. The Politics of Truth. Oxford: Oxford University Press, 2008. 